\title{
EVOLUTIONARY CONSERVATION OF CHYMOTRYPSINOGEN GENE: GENOMIC ANALYSIS AND PROTEIN MODELING
}

\author{
De-Xing Hou, ${ }^{1, *}$ Yifei Wang, ${ }^{1}$ Hideji Yamashita, ${ }^{2}$ \\ Shin OKamoto, ${ }^{2}$ Kazushige Yokoyama, ${ }^{1}$ Eiichi Soeda, ${ }^{1}$ \\ and Akinori SARAI ${ }^{1}$ \\ ${ }^{1}$ Gene Bank, Tsukuba Life Science Center, The Institute of Physical and Chemical \\ Research (RIKEN), Koyadai, Tsukuba, Ibaraki 305, Japan \\ ${ }^{2}$ Department of Agricultural Sciences and Natural \\ Resources, Faculty of Agriculture, Kagoshima \\ University, Kagoshima 890, Japan
}

\begin{abstract}
Summary Chymotrypsinogen is widely present in various animal pancreases. To study evolutionary relationship of chymotrypsinogen gene in species, we used a cDNA probe of human prechymotrypsinogen to investigate the species distribution of chymotrypsinogen gene, and designed oligodeoxynucleotide primers to investigate the genomic organization in the three domains of active sites. The genomic analyses showed that chymotrypsinogen gene is evolutionary conserved in species. On the basis of the deduced amino acid residues, a three-dimensional model for human chymotrypsinogen was further built by computer graphics. The model showed high similarity to the X-ray crystal structure of bovine chymotrypsinogen $\mathrm{A}$, thus, demonstrated that the three-dimensional structure is more conserved in evolution than protein sequences.
\end{abstract}

Key Words chymotrypsinogen gene, zoo blot analysis, polymerase chain reaction (PCR), three-dimensional model

\section{INTRODUCTION}

Chymotrypsin [EC 3.4.21.1] is a digestive enzyme that hydrolyzes proteins in the small intestine. Its inactive precursor, chymotrypsinogen, is synthesized in the acinar cell of pancreas. When the cell is stimulated by a hormonal signal or a nerve impulse, the zymogen is secreted into the duodenum and is activated by

Received November 2, 1993; Revised version accepted April 15, 1994.

* To whom correspondence should be addressed. 
tryptic cleavage. Chymotrypsinogen has been studied extensively at protein and enzyme levels in mammals, especially in the preparation from bovine. The threedimensional structure of bovine chymotrypsinogen has been determined by X-ray crystallographic methods (Cohen et al., 1981; Wang et al., 1985). The phylogenetic differences of chymotrypsin(ogen) have been observed in a number of diverse species (Neurath et al., 1967; Bhargava and Barnard, 1973; Haën et al., 1975). However, there is little information concerned its genetics at gene level.

Chymotrypsinogen cDNAs for canines (Pinsky et al., 1983), rat (Bell et al., 1984), and human (Tomita et al., 1989) have been cloned, their nucleotide sequences and the deduced amino acid residues have been determined. Recently, we have cloned a genomic gene for human chymotrypsinogen and mapped this gene in human chromosome 16q23 (Hou et al., 1993). In the present study, we describe the evolutionary conservation of chymotrypsinogen gene in species by (1) investigating the species distribution of chymotrypsinogen gene, (2) investigating the genomic organization in the three domains of active sites, and (3) building a threedimensional model for human chymotrypsinogen.

\section{MATERIALS AND METHODS}

Extraction of DNA and Southern blot analysis. DNA from human CGM-1 was extracted from cultured cells, and DNAs of bovine and chicken (Gifu native fowl) were extracted from normal male blood as described previously (Maniatis et al., 1989). High-molecular-weight. DNAs were digested with 5 units of EcoRI restriction enzyme per microgram of DNA, as recommended by the manufacturer. Aliquots of $13 \mu \mathrm{g}$ of each digested DNA were fractionated by electrophoresis in a $0.8 \%$ agarose gel and transferred to a nylon membrane. The human prechymotrypsinogen cDNA containing the entire protein-coding sequences (Tomita et al., 1989) was radiolabeled with $\left[\alpha^{32} \mathrm{P}\right] \mathrm{dCTP}$ by the random primer labeling method (Feinberg and Vogelstein, 1983), and then hybridized to the membrane overnight at $65^{\circ} \mathrm{C}$ in $6 \times \mathrm{SSC}, 5 \times$ Denhardt's, $10 \%$ dextran sulfate, $1 \% \mathrm{SDS}$, plus $100 \mu \mathrm{g} / \mathrm{ml}$ sonicated salmon sperm DNA as described elsewhere (Maniatis et al., 1989). After hybridization, the membrane was washed once in $2 \times \mathrm{SSC}$ at room temperature and twice in $0.1 \times \mathrm{SSC}$ and $0.1 \% \mathrm{SDS}$ at $65^{\circ} \mathrm{C}$ for $15 \mathrm{~min}$ each, and then exposed to Kodak XAR-5 film with an intensifying screen.

Primer synthesis and PCR analysis. Six sets of oligodeoxynucleotide primers spaced at intervals along the human prechymotrypsinogen cDNA were synthesized with an Applied Biosystems 380B DNA Synthesizer and subsequently purified by OPC column. The PCR primers are shown as follows:

$\begin{array}{llc}\text { No. } & \text { Primer pair (forward/reverse) } & \text { Product (bp) } \\ \text { I } & \text { 5'-GACAAAACCGGCTTCCACTTCTGC-3' } & 80 \\ & \text { 5'-GACCCCGCAGTGGGCAGCGGTGAC-3' } & \\ \text { II } & \text { 5'-GTCTTCAAG-AACCCCAAGTTCAGC-3' } & 181\end{array}$




\begin{tabular}{lll} 
& \multicolumn{4}{c}{ 5'-GTTGTA-CTTGGTCTTGCCCCAGCC-3' } & \\
III & 5'-CTGGTCTGCCAAAAGGATGGAGCC-3' & 140 \\
& 5'-GTTGGCAGCCAGGATCTTCTGCAC-3' & \\
IV & 5'-GGGCTCCCTCATCAGCGAGGAC-3' & 30 \\
& 5'-CACCCAGTCCTCGCTGATGAGGGA-3' & \\
V & 5'-ATTCTGACCGTGAACAATGACATC-3' & 133 \\
& 5'-TGTGGTGGCACACAGTGTCCCCGC-3' & \\
VI & 5'-TGGACCCTGGTGGGCATTGTGTCC-3' & 92 \\
& 5'-CCAAGGTATGAGCTTGGTGACACG-3'
\end{tabular}

The template DNAs for PCR (PCRable-mammalian DNA, Lot 51) were purchased from Bios Inc. The PCR reactions were performed on a GeneAmp PCR System 9600 (Perkin-Elmer-Cetus), and the PCR reaction mixture contained 10 $\mathrm{mM}$ Tris- $\mathrm{HCl}(\mathrm{pH} 8.3), 50 \mathrm{mM} \mathrm{KCl}, 1.5 \mathrm{~mm} \mathrm{MgCl}_{2}, 0.01 \%$ gelatin, $200 \mu \mathrm{M}$ each dNTP, $100 \mathrm{ng}$ each primer, and $2.5 \mathrm{U}$ of Taq polymerase (Perkin-Elmer) in a volume of $50 \mu \mathrm{l}$. After DNA was denatured at $94^{\circ} \mathrm{C}$ for $2 \mathrm{~min}, 35$ cycles of PCR were performed, each cycle consisting of a $20-\mathrm{s}$ denaturation at $94^{\circ} \mathrm{C}$, a $20-\mathrm{s}$ annealing at $65^{\circ} \mathrm{C}$, and 30 -s extension at $72^{\circ} \mathrm{C}$. Final extension was carried out at $72^{\circ} \mathrm{C}$ for 5 min. Five microliter of amplified DNA was electrophoresed in a $3 \%$ agarose gel in $1 \times$ TAE buffer.

Protein modeling. A three-dimensional model for human chymotrypsinogen was built by computer graphics based on X-ray crystal structure of bovine chymotrypsinogen $\mathrm{A}$ and the deduced amino acid residues of human chymotrypsinogen cDNA. Computer modeling processes were performed on an Iris-4D graphics system by Silicon Graphics using the SYBYL molecular modeling software from Tripos Associates Inc. The atomic-coordinate's datafile of the bovine chymotrypsinogen A, access code 2CGA, was obtained from the Brookhaven Data Bank (Bernstein et al., 1977). The three-dimensional structure of bovine chymotrypsinogen $\mathrm{A}$ was used as a template, and the amino acid residues were substituted by corresponding residues of human chymotrypsinogen that were obtained from the deduced amino acids of cDNA (Tomita et al., 1989). Because substitution of residues will often result in bad contacts among the atoms of the side chains, we first relaxed the bad geometry in the side chain ring of the proline residues, and then relaxed the side chains of other amino acid residues using FIX SIDECHAINS routine in SYBYL. After these processes were finished, an initial model was built for the human chymotrypsinogen. To adjust bond lengths and angles to be more optimal values, the initial model was subjected to stereochemical regularization by use of the SHAKE procedure (Haneef et al., 1989). After loading charge and adding hydrogen atoms, the initial model was subjected to energy minimization with the procedure MAXIMIM2 until the gradient RMS (root mean square) deviation value and displacement RMS value of all atoms were less than $0.05 \mathrm{kcal} /(\mathrm{mol}$. $\AA$ ) and $0.001 \AA$, respectively. Thus, the final model could be built for human chymotrypsinogen. 


\section{RESULTS AND DISCUSSION}

Species distribution of chymotrypsinogen gene

Chymotrypsinogen is widely present in various animal pancreases. To determine the present form of chymotrypsinogen gene in species, Southern blot analysis was performed on EcoRI-digested genomic DNAs from human, bovine, chicken and rat with a cDNA probe of human prechymotrypsinogen. As shown in Fig. 1, human (lane 1) and bovine (lane 2) DNAs had two hybridizing EcoRI-fragments while chicken (lane 3) and rat (lane 4) DNAs had a single well-conserved fragment. Our previous studies have identified that the $10-\mathrm{kb}$ EcoRI fragment from human genome encoded chymotrypsinogen gene while the $14-\mathrm{kb}$ fragment appeared to be a duplication gene of chymotrypsinogen (Hou et al., 1993). This duplication of chymotrypsinogen gene is most likely related to multiple forms of chymotrypsinogen present in the species because two chymotrypsinogens have been isolated from human (major and minor types, Caro et al., 1975) and bovine pancreases (A and B types, Wilcox, 1970) while only one chymotrypsinogen has been isolated from chicken (Ryan et al., 1965) and rat pancreases (Bell et al., 1984). Chymotrypsin(ogen) is widely distributed in various species, from vertebrates to invertebrates. Although zoo blot analysis from other species was not performed because of limited DNA sources, chymotrypsinogen gene would be conserved with corresponding forms, e.g., by gene duplication.

Evolutionary conservation of the gene sequences for three active-sites

The catalytic activity of chymotrypsin depends on a serine (Ser-195)-histidine

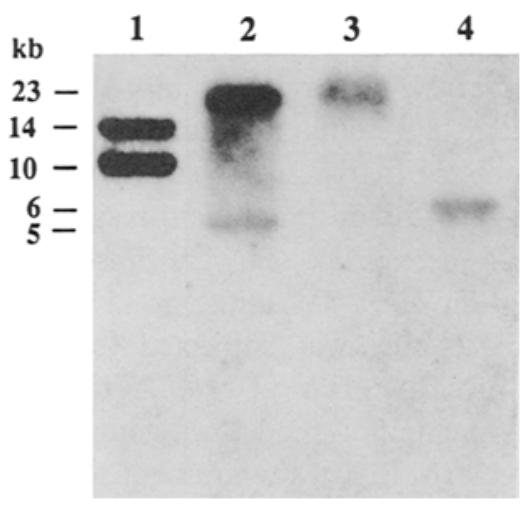

Fig. 1. Southern blot analysis of DNAs from human CGM-1 (lane 1), bovine (lane 2), chicken (lane 3), and rat (lane 4) which were digested with EcoRI and hybridized with a cDNA probe of human prechymotrypsinogen The sizes of the hybridization bands are indicated in the left with kilobase $(\mathrm{kb})$. 
(His-57)-aspartate (Asp-102) triad. The comparisons of amino acid sequences indicated that these three domains have different percentage of identity (from 75 to $96 \%$ ) between human, bovine, canine, and rat. Furthermore, it has been reported that these three domains were encoded by separated exons (exons 3, 5, and 7 , respectively) in rat genome. These results prompted us to investigate their genomic variability by PCR. Six oligodeoxynucleotide primer sets (see MATERIALS AND METHODs and Fig. 2A), guided in part by the known exon-intron structure of the rat chymotrypsin B gene (Bell et al., 1984), were designed. As shown in Fig. 2B, the primer set I (flanking the active-site His-57) detected a $80 \mathrm{bp}$ band from

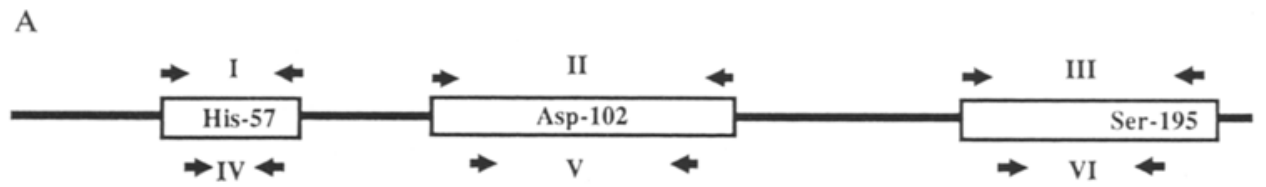

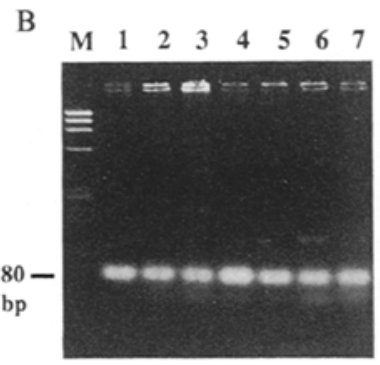

I

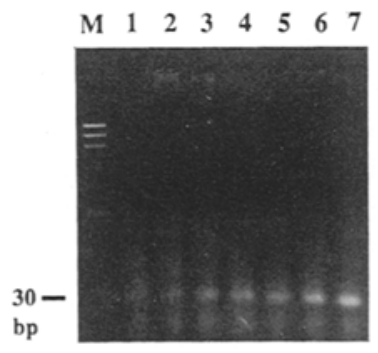

IV

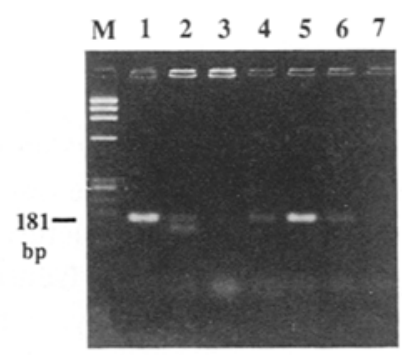

II

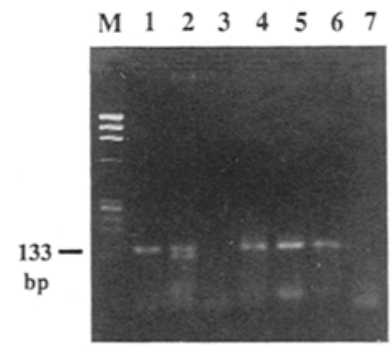

$\mathrm{V}$

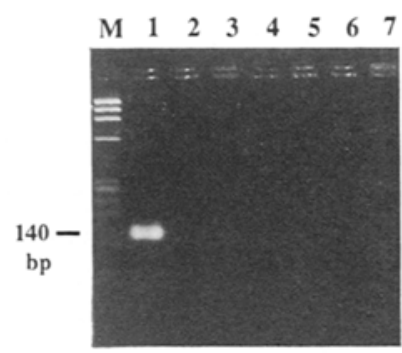

III

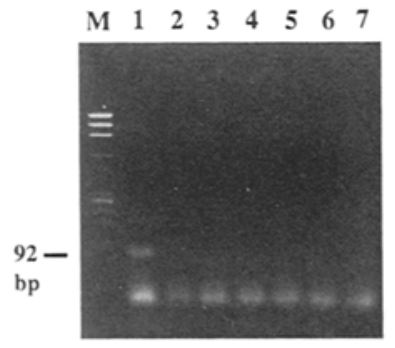

VI

Fig. 2. (A) Schematic representation of PCR primer locations along human chymotrypsinogen cDNA. The open boxes represent the three domains containing active sites. The primer sets are illustrated. (B) PCR analysis of chymotrypsinogen gene in seven species. Their genomic DNAs were used as templates and amplified with six sets of oligodeoxynucleotide primers (I-VI). Amplified DNAs were analyzed by electrophoresis in a $3 \%$ agarose gel. The PCR products from human CGM-1 (lane 1), horse (lane 2), chicken (lane 3), mouse (lane 4), bovine (lane 5), dog (lane 6), and rat (lane 7) are indicated in the left with basepair (bp). The molecular weight standard (M) is $ø$ X174 DNA digested with HaeIII. 
all of seven species; the primer set II (flanking the active-site Asp-102) detected a clear 181 bp band from human (lane 1) and bovine (lane 5) DNAs and a faint band from horse (lane 2), mouse (lane 4), and dog (lane 6) DNAs; the primer set III (flanking the active-site Ser-195) detected a 140 bp band only in human DNA (lane 1). To confirm these results, we further used another PCR primer set (IV, $\mathrm{V}$, and VI) in each of the three domains. Their PCR products showed the same patterns in above seven species (Fig. 2B, bottom). It is known that these three domains were encoded by separated exons, and the sequence homology of the domain I (92-95\%) was higher than that of domains II (79-85\%) and III (78-82\%) between human, dog, and rat. Thus, the species that displayed no PCR products with these primers would have different genomic structure in these three domains with human. Of course, genomic sequencing will be necessary to investigate their genomic variability in detail. Novelly, the primer set III was designed by starting from 3'-coding region of the human cDNA, and it showed specific amplification to human DNA. Thus, this primer set could be used as a sequence tagged site (STS) to detect human chymotrypsinogen gene (Hou et al., 1993).

\section{A conserved three-dimensional model structure for human chymotrypsinogen}

Evolutionary conservation of a gene can also be observed in its protein product. Many studies have reported that the primary structure of chymotrypsinogen also shows evolutionary conservation among species (Neurath et al., 1967; Bhargava and Barnard, 1973; Haën et al., 1975). Recently, computer graphics techniques have been developed to build three-dimensional model and to investigate the structural evolution of proteins (Chothia and Lesk, 1986; Haneef et al., 1989). The three-dimensional structure of bovine chymotrypsinogen A should be an appropriate template to build three-dimensional model of human chymotrypsinogen because they showed $82 \%$ identity of amino acid sequences, the important residues for function and structure of the protein are well conserved (e.g., three active-sites of His-57, Asp-102, and Ser-195), and no deletions occur in the amino acid sequences (data reviewed but not shown). Here, we built a three-dimensional model for human chymotrypsinogen, based on X-ray crystal structure of bovine chymotrypsinogen A (Wang et al., 1985) as a template, by computer graphics and energy minimization techniques. The stereoview of the optimally superimposed $\mathrm{C} \alpha$ traces of human (cyan line) and bovine chymotrypsinogen A (red line) is shown in Fig. 3. The three-dimensional model of human chymotrypsinogen shows high similarity to that of bovine chymotrypsinogen A because all of the intrachain disulfides and ten cysteines that contribute to establish the tertiary structure of the protein are fully conserved. Some differences are also observed in the surface of the model between human and bovine, and they are due to substitution of some residues, e.g., substitution of nine serine residues of bovine chymotrypsinogen $\mathrm{A}$ by other amino acid residues, and eight non-basic residues by basic residues. Furthermore, the three residues of active-sites (Ser-195, His-57, and Asp-102) are forming a 


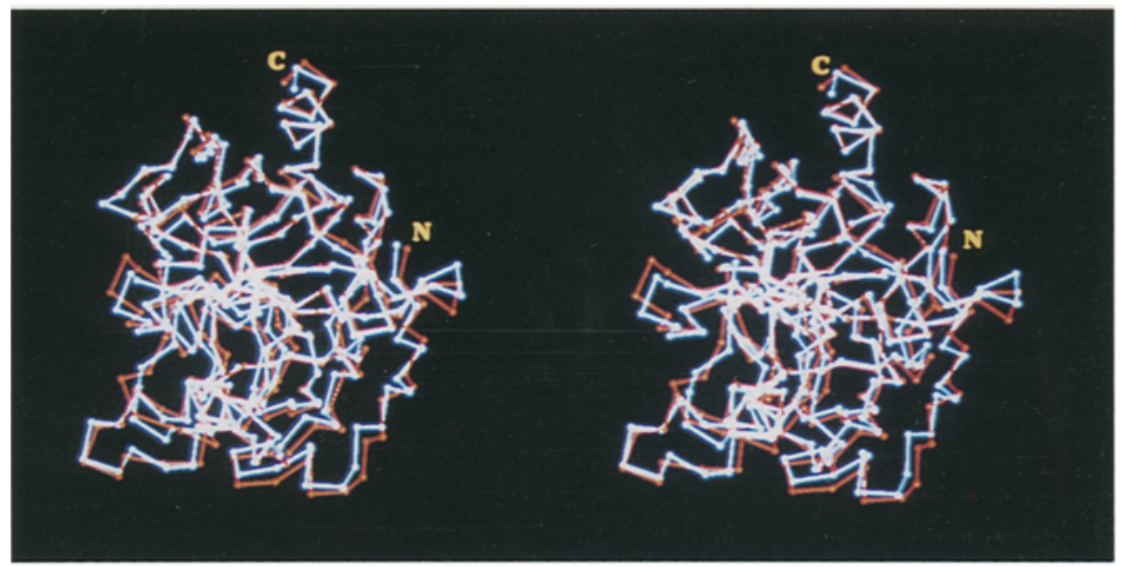

Fig. 3. Stereoview of the optimally superimposed $\mathrm{C} \alpha$ traces of the human chymotrypsinogen (cyan line) and bovine chymotrypsinogen (red line). The RMS (root mean square) deviation from all of main-chain atoms was $0.9193 \AA$. The $\mathrm{N}$ and C-terminal residues are indicated with " $N$ " and " $C$ " characters.

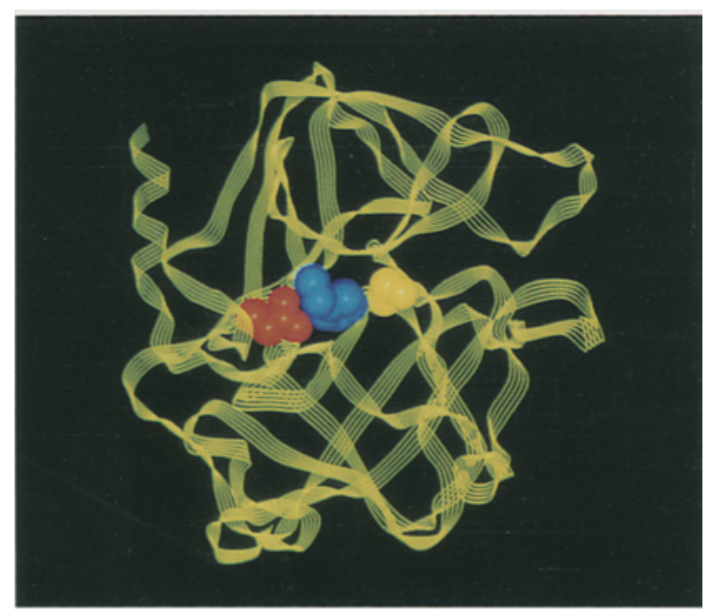

Fig. 4. Ribbon diagram of the human chymotrypsinogen. The residues of active-sites are represented with blue (His-57), red (Asp-102), and orange spheres (Ser-195), respectively. The residues from Ile-235 to Asn-245 of C-terminal fragment forme a short helix.

catalytic triad (Fig. 4), which is very similar to that of bovine chymotrypsinogen A. The RMS (root mean square) deviation for all of main-chain atoms was very small, only $0.92 \AA$, between bovine and human. Thus, these results also demonstrate that the three-dimensional structure is more conserved in evolution than protein sequences (Chothia and Lesk, 1986). Regarding the relationship between structure and function of human chymotrypsinogen will be discussed in detail by another paper. 
Acknowledgments This study was supported by the human genome research program o RIKEN and the Science and Technology Agency of Japan.

\section{REFERENCES}

Bell GI, Quinto C, Quiroga M, Valenzuela P, Craik CS, Rutter W (1984): Isolation and sequence of a rat chymotrypsin B gene. J Biol Chem 259 : 14265-14270

Bhargava AK, Barnard EA (1973): Evolution in the pancreatic chymotrypsinogen series: N-terminal sequence determinations and comparisons. J Mol Biol 2: 187-198

Bernstein FC, Koetzle TF, Williams GJB, Meyer EF, Brice MD, Rodgers JR, Kennard O, Shimanouchi T, Tasumi M (1977): The Protein Data Bank: A computer-based archival file for macromolecular structures. J Mol Biol 112: 535-542

Caro AD, Figarella C, Guy O (1975): The two human chymotrypsinogens purification and characterization. Biochim Biophys Acta 379: 431-443

Chothia C, Lesk AM (1986): The relation between the divergence of sequence and structure in protein. EMBO J 5: 823-826

Cohen GH, Silverton EW, Davier DR (1981): Refined crystal structure of gamma-chymotrypsin at 1.9 angstroms resolution. J Mol Biol 148: $449-479$

Feinberg AP, Vogelstein B (1983): A technique for radiolabeling DNA restriction endonuclease fragments to high specific activity. Anal Biochem 132: 6-13

Haneef I, Talbot SJ, Stockley PG (1989): Modeling loop structures in proteins and nucleic acids: an RNA stem-loop. J Mol Graphics 7: 186-195

Haën CD, Neurath H, Teller DC (1975): The phylogeny of trypsin-related serine protease and their zymogens. New methods for the investigation of distant evolutionary relationship. J Mol Biol 92: 225-259

Hou D-X, Ozawa K, Tomita N, Maeda Y, Hashiguchi T, Yokoyama K, Soeda E (1993): Genomic cloning and partial characterization of human chymotrypsinogen gene. Jpn $\mathbf{J}$ Human Genet 38: $371-380$

Maniatis T, Fritsch EF, Sambrook J (1989): Molecular Cloning: A Laboratory Manual (2nd ed), Cold Spring Harbor Laboratory Press, New York

Neurath $\mathrm{H}$, Walsh KA, Winter WP (1967): Evolution of structure and function of proteinase. Science 158: $1638-1644$

Pinsky SD, LaForge S, Luc V, Scheele G (1983): Identification of cDNA clones encoding secretory isoenzyme forms: Sequence determination of canine pancreatic prechymotrypsinogen $2 \mathrm{mRNA}$. Proc Natl Acad Sci USA 80: 7486-7490

Ryan CA, John JC, Tomimatsu Y (1965): Chicken chymotrypsin and turkey trypsin, Part II: physical and enzyme properties. Arch Biochem Biophys 110: 175-183

Tomita N, Izumoto Y, Horii A, Doi S, Yokouchi H, Ogawa M, Mori T, Matsubara, K (1989): Molecular cloning and nucleotide sequence of human pancreatic prechymotrypsinogen cDNA. Biochem Biophys Res Commun 158: 569-574

Wang D, Bode W, Huber R (1985): Bovine chymotrypsinogen A X-ray crystal structure analysis and refinement of a new crystal form at $1.8 \AA$ resolution. J Mol Biol 158: 595-624

Wilcox PE (1970): Chymotrypsinogens-chymotrypsin. Perlmann GE, Lorand L (eds). Methods in enzymology, Vol 19, pp 64-108, Academic Press, New York 